2. Jain, S. K. and Nigam, N. C., Historical developments and current status of earthquake engineering in India. 12th World Congress on Earthquake Engineering, Auckland, New Zealand, 2000.

3. Jain, S. K., Indian earthquakes - an overview. Indian Concr. J., 1998, 72, 555-561.

4. Pinchao, L., Liuxin, J., Bingsheng, L., Changtao, C., Dongping, F., Peilun, R. and Mengchun, Z., A cognitive perspective on the safety communication factors that affect worker behavior. J. Build. Constr. Plann. Res., 2014, 2, 183-197.

5. Vicente, K. J., Cognitive Work Analysis, Lawrence Erlbaum Associates, Mahwah, New Jersey, London, 1999.

6. Rajendran, C. P., John, B., Sreekumari, K. and Rajendran, K., Reassessing earthquake hazard in Kerala based on the historical and current seismicity. J. Geol. Soc. India, 2009, 73, 785-802.

7. McClure, J., White, J. and Sibley, C. G., Framing effects on preparation intentions: distinguishing actions and outcomes. Disaster Prevent. Manage., 2009, 18, 187-199.

8. Tena-Colunga, A. and López-Blancas, A., Allowable torsional eccentricity for the simplified method for the seismic analysis of low-rise confined masonry shear - wall buildings of Mexican Codes. Open Civ. Eng. J., 2011, 5, 132-142.

9. Eiser. J. R. et al., Risk interpretation and action: a conceptual framework for responses to natural hazards. Int. J. Disaster Risk Reduction, 2012, 1, 5-16.

\section{Performance of sorghum genotypes under zero tillage conditions in rice fallows with reference to stem borer Chilo partellus}

\author{
P. Yogeswari ${ }^{1}$, C. Sandhya $\operatorname{Rani}^{1, *}$ and \\ G. Ramachandra Rao ${ }^{2}$ \\ ${ }^{1}$ Department of Entomology, Agricultural College, \\ Bapatla 522 103, India \\ ${ }^{2}$ Department of Environmental Science, \\ Advanced Post Graduate Centre, Lam, Guntur 522 034, India
}

A field experiment was carried out to screen the sorghum genotypes against stem borer in rice fallow under zero tillage condition. Based on mean stem tunnel length, the genotypes were categorized as least susceptible $(0-5 \mathrm{~cm})$, moderately susceptible $(5-10 \mathrm{~cm})$ and highly susceptible $(>10 \mathrm{~cm})$. The resistant check CSH 16 (C) was found least susceptible with $4.65 \mathrm{~cm}$, whereas NTJ-2 (C), NLCW-6 and N-14 were found to be highly susceptible as they recorded $10.45,10.46$ and $11.44 \mathrm{~cm}$ mean stem tunnel length respectively. The

\footnotetext{
*For correspondence. (e-mail: gajularamatha@gmail.com)
}

remaining genotypes were moderately susceptible with $6.60-9.84 \mathrm{~cm}$ mean stem tunnel length. There was non-significant positive correlation between the number of larvae and leaf damage, dead hearts, stem tunnelling, white ears and chaffy grains respectively, but it was negative for tiller damage.

Keywords: Genotypes, sorghum, stem borer, stem tunnel length, susceptible.

SoRGHUM [Sorghum bicolor (L.) Moench] is the fifth major cereal crop after wheat, rice, maize and barley. It is the most important crop of Asia, Africa, Australia, America and is cultivated as a staple crop in the semi-arid tropics (SAT). In India, it is cultivated in an area of $6.18 \mathrm{~m}$ ha with 5.33 million tonnes $(\mathrm{mt})$ production and productivity of $863 \mathrm{~kg} /$ ha (ref. 1). In general sorghum is cultivated during kharif, maghi (late kharif) and rabi seasons in Andhra Pradesh (AP) in an area of 287,000 ha with production of 546,000 tonne and productivity of $1904 \mathrm{~kg} / \mathrm{ha}$ (ref. 2) as against normal area of 760,000 ha with production of 552,000 tonne and productivity of $730 \mathrm{~kg} / \mathrm{ha}$. The reasons for low productivity under normal type of cultivation might be due to shifting of jowar area to cultivation of commercial crops, high humidity in the coastal regions, and ravage due to pests and diseases in jowar-cultivating areas.

Insect pest conditions are dynamic in nature and change with climate and farming practices - introduction of improved varieties has been known to result in pest outbreaks or changes in pest status ${ }^{3}$. Sorghum is attacked by more than 150 insect species causing $32 \%$ crop loss ${ }^{4}$. Losses in sorghum due to insect pests differ on a regional basis and have been estimated at US\$ 1089 million in the SAT, US\$ 250 million in USA and US\$ 80 million in Australia ${ }^{5}$. Among the insect pests, shoot fly, Atherigona soccata (Rondani) and stem borer, Chilo partellus (Swinhoe) are the major threats causing $75.6 \%$ and $24.3-36.3 \%$ yield loss respectively ${ }^{6}$.

Management of the pests is being done using pesticides. However, due to the adverse effects of pesticides, it is imperative to seek for alternate integrated pest management methods like host plant resistance, which it not only cost-effective and does not require application skills in pest control techniques, but also enhances the effectiveness of natural enemies and reduces the need to use pesticides $^{7}$. The effect of resistant genotypes on insect population is continuous and cumulative over time. Umakanth et al. ${ }^{8}$ reported 'SPV 1022', 'PKV809' and 'CO28' as promising sorghum cultivars in rice fallows.

Performance of sorghum genotypes under zero tillage conditions in rice fallows with reference to stem borer was carried out during rabi 2014-15 in the southern block of Agricultural College Farm, Bapatla, Guntur district, AP. Studies were carried out to screen the sorghum genotypes against shoot fly in rice fallow under zero 
tillage condition. Twenty genotypes were procured from the Directorate of Sorghum Research, Hyderabad, Telangana, and Regional Agricultural Research Station (RARS), Nandyal, AP to be used as source material for the screening study. The experiment was laid out in randomized block design at Agricultural college Farm, Bapatla and the treatments were replicated twice. The crop was sown on 7 January 2015. The length of each line was $4 \mathrm{~m}$ and spacing between two lines of each genotype was $45 \mathrm{~cm}$; also intra-row spacing adopted was $15 \mathrm{~cm}$.

Observations were recorded on number of larvae per plant by destructive sampling at vegetative, flowering grain formation and harvesting stages, dead hearts caused by $C$. partellus (number of plants with dead hearts symptoms and total number of plants were recorded from each plot based on which per cent dead hearts was calculated from 30 to 60 DAS at weekly intervals), per cent damaged leaves (number of leaves with leaf injury symptoms like scraping, shot holes and total number of leaves were recorded from each plot based on which per cent leaf injury was calculated from 30 to 60 DAS at weekly intervals), damage caused by $C$. partellus in tillers (damaged tillers and total number of tillers per hill were recorded and per cent tiller damage was calculated) and stem tunnelling (at the time of harvesting, by destructive sampling, the main stems of plants infested with $C$. partellus were split open from the base to the apex, and cumulative tunnel length and stem length were measured; $\mathrm{cm}$ ). The percentage tunnelling was calculated using the formula given below.

$$
\frac{\text { Length of tunnelling }(\mathrm{cm})}{\text { Total length of stem }(\mathrm{cm})} \times 100 \text {. }
$$

Genotypes were categorized based on stem tunnelling according to Rajasekhar and Srivastav ${ }^{9}$ (Table 1).

The number of white ears/plot (number of white ears due to stem borer infestation per plot from the total number of plants sampled was recorded and percentage white ears was calculated), chaffy grain percentage (total number of grains from each ear head and chaffy or under developed grains in randomly selected five ear heads from each plot were counted and per cent chaffy grain was calculated) and number of larvae and pupae per stubble after harvest (to know the carry-over population of $C$. partellus, data on number of larvae and pupae per stubble after harvest were recorded) were recorded.

Table 1. Particulars of stem tunnel length range for the damage by stemborer

\begin{tabular}{ll}
\hline Range of mean tunnel length $(\mathrm{cm})$ & \multicolumn{1}{c}{ Attribute } \\
\hline $0-5$ & Least susceptible \\
$5-10$ & Moderately susceptible \\
$>10$ & Highly susceptible \\
\hline
\end{tabular}

Genotypes exhibited significant variation pertaining to larval incidence during their crop growth period. The number of larvae per plant recorded at vegetative stage ranged from 5.00 to 8.90 . The highest number of larvae was recorded in genotype $\mathrm{CSH} 23$ (8.90) followed by CSV 15 (8.50), SSV 84 (7.80), CSH 14 (7.80) and CSH 20MF (7.50), whereas the lowest number of larvae was recorded in genotypes $\mathrm{CSH} 24 \mathrm{MF}, \mathrm{CSH} 25, \mathrm{NTJ}-4$ (C) (5.00 each) followed by CSH 13 (5.10), N-14 (5.20) and BRJ-358 (5.60) compared to the resistant check CSH 16 (5.80) and Mahalaxmi 296 (6.80).

At flowering stage, the number of larvae per plant ranged from 4.50 to 11.40 . The highest number of larvae was recorded in genotype SSV 84 (11.40) followed by CSH 22SS (10.90), CSV 26 (9.90) and CSV 24SS (9.60). The lowest number of larvae was recorded in genotype $\mathrm{N}-14$ (4.50) followed by NTJ-2 (C) (5.10), N-13 (5.90) and resistant check CSH 16 (C) (6.20), when compared to the popular check Mahalaxmi 296 (7.90) (Table 2).

At harvesting stage, the number of larvae per plant ranged from 3.20 to 7.60 . The highest number of larvae was recorded in NTJ-4 (C) (7.60) followed by NLCW-6 (6.70), NLCW-8 (6.60) and BRJ-358 (6.50), whereas the lowest number of larvae per plant was recorded in genotype CSV 15 (3.20) followed by CSH 23, CSH 30 (3.40 each), CSV 29R (3.50) and SSV 84 (3.70) compared to the resistant check CSH 16 (4.0), NTJ-3 (4.40) and popular check Mahalaxmi 296 (4.80). Mohan et al. ${ }^{10}$ reported the highest seasonal incidence of $C$. partellus on variety HC-136 and JS-20 during rabi-summer and kharif, and high larval and pupal populations during kharif season crop than in rabi-summer. Adverse effect of resistant genotypes on insect development resulted in low larval mass due to nutritional abnormalities and/or because of poor food utilization by the larvae of resistant varieties ${ }^{11}$. Painter $^{12}$ suggested that with rare exceptions, the feeding of insects during the developmental stages on resistant varieties results in individuals that are smaller and having less weight. The sorghum varieties appear to possess some antibiotic factors, which exist either in the leaves or in the stem, or in both, and adversely influence larval duration ${ }^{13}$.

Prolongation of larval period ultimately results in reduction of the number of generations in a season/year. The adverse effects on the post-embryonic development of stem borer might possibly be because of the antibiotic factors ${ }^{14}$. Thus, it can be concluded that the adverse effects of the resistant genotypes on larval and pupal mass, prolonged larval and pupal period and low population and adult emergence may be due to some nutritional abnormalities.

At $42 \mathrm{DAE}$, the number of dead hearts and per cent dead hearts ranged from 0.00 to 0.02 and 0.00 to 2.22 respectively. The highest number of dead hearts and per cent dead hearts were observed in genotypes CSV $22(0.02$ and 2.22), and N-13 (0.02 and 2.18) followed by CSV 


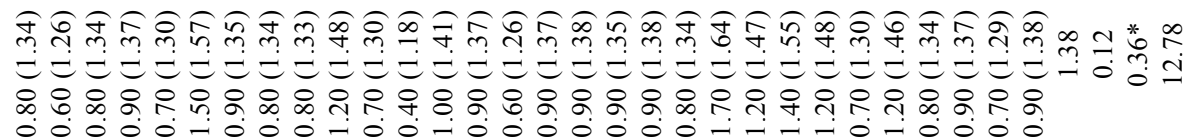

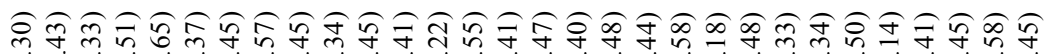

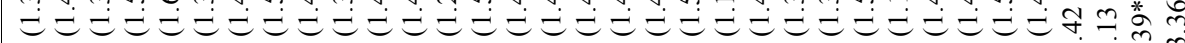

$\dot{z}$

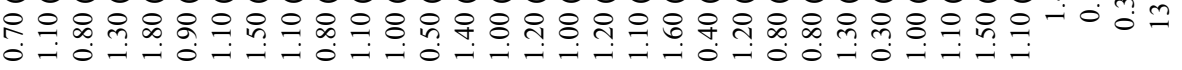

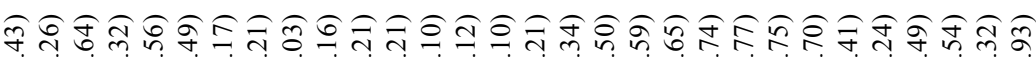

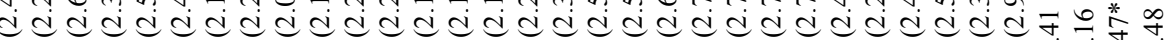

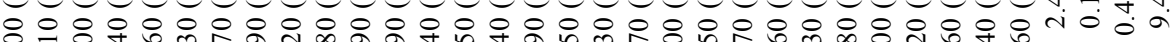

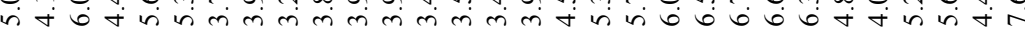

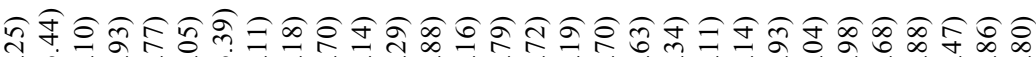

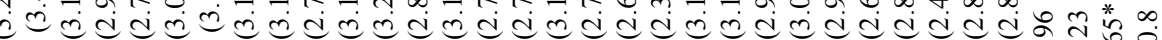

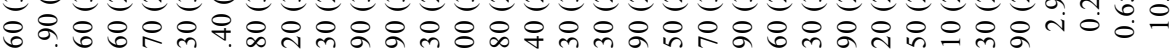
茫

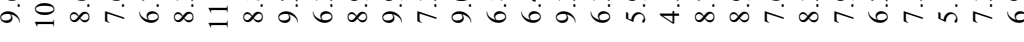

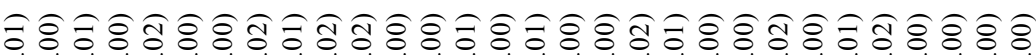

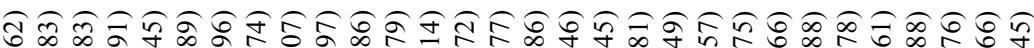
did d d d d d d d d d d d d d d d d d d d d d d d d d d d

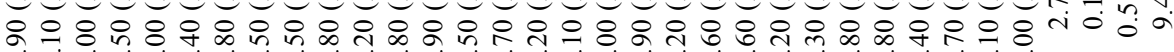

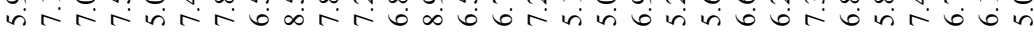

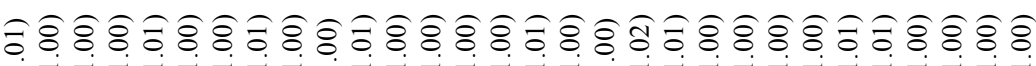

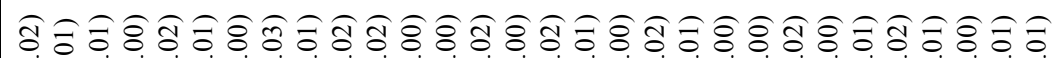

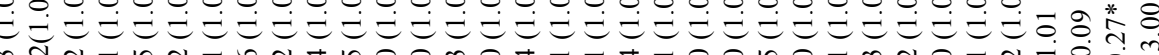

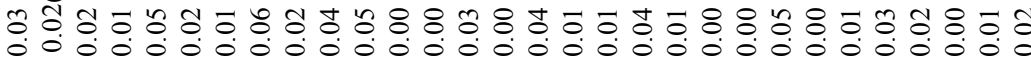

1

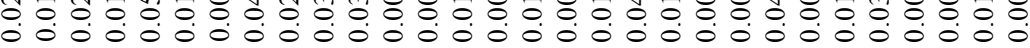

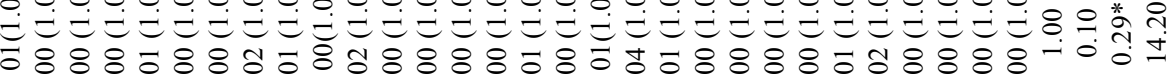

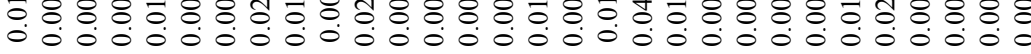

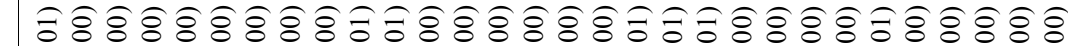

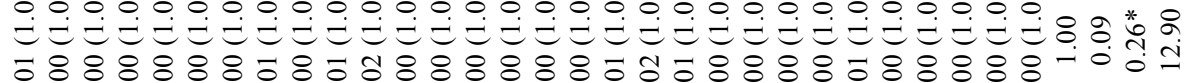

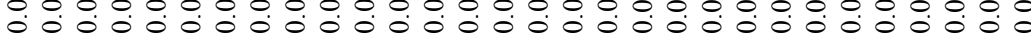

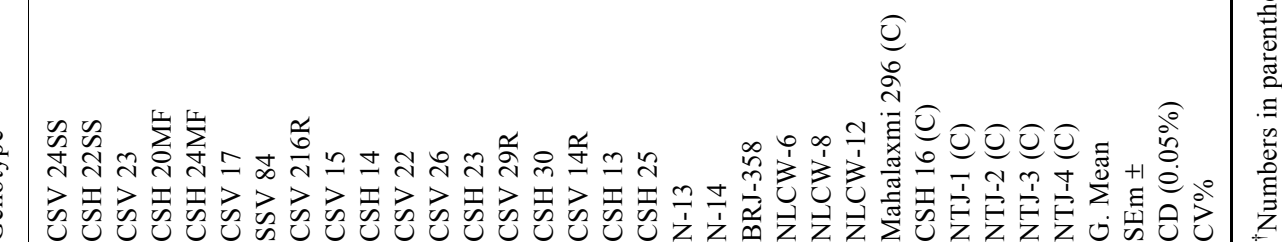




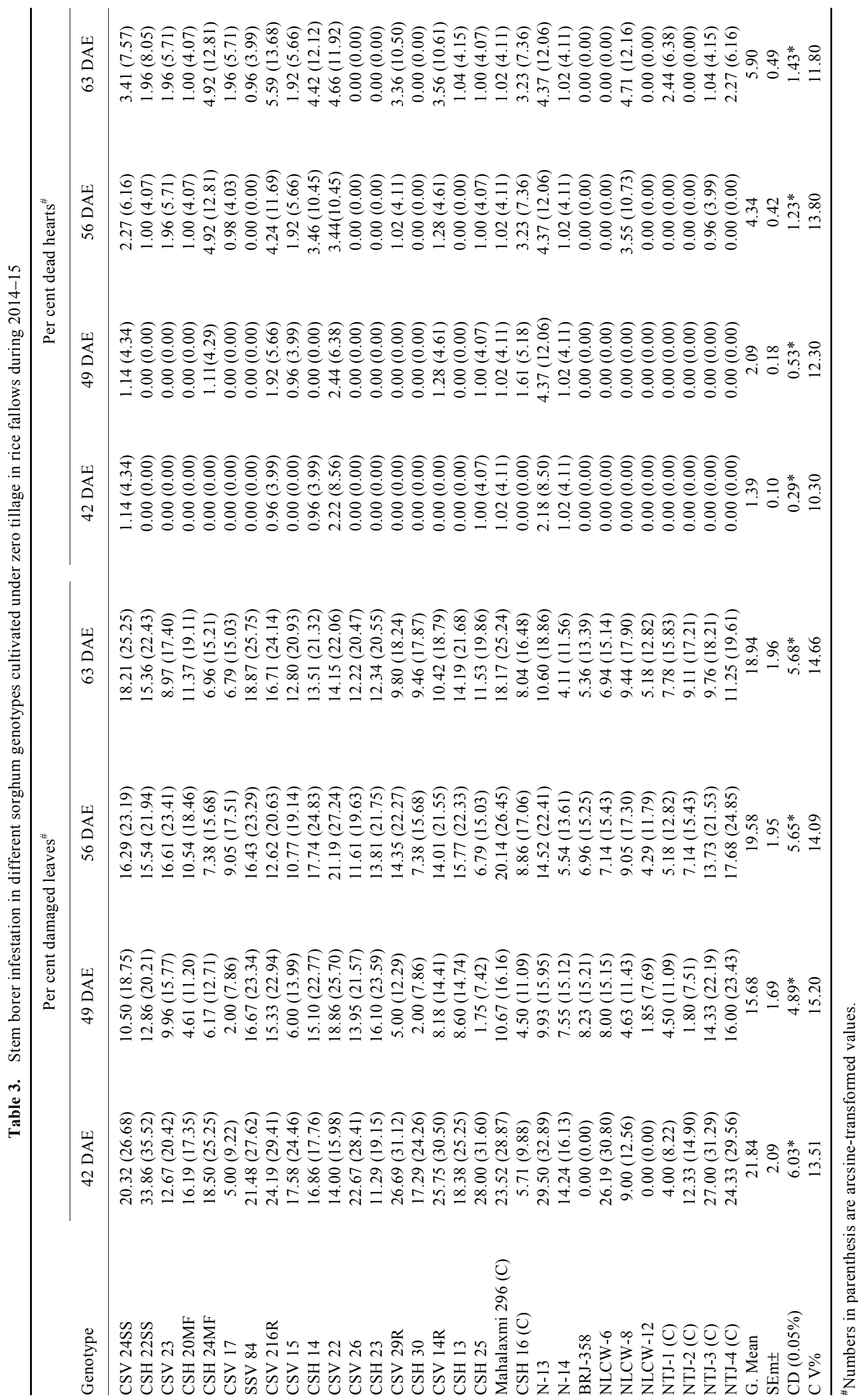


216R (0.01 and 1.14), CSH 25 (0.01 and 1.00), N-14 and popular check Mahalaxmi 296, resistant check CSH 16 (C) (0.01 and 1.02) and CSV 24SS (0.01 and 1.14). No infestation was recorded in the remaining genotypes (Table 3).

At 49 DAE, the number of dead hearts and per cent dead hearts ranged from 0.00 to 0.04 and 0.00 to 2.44 respectively. The highest number of dead hearts and per cent dead hearts were observed in genotype N-13 (0.04 and 4.37) followed by CSV 22 (0.02 and 2.44), CSV 216R, popular check Mahalaxmi 296 (0.02 and 1.61), CSV 216R (0.02 and 0.96) and N-14 and CSH 25 (0.01 and 1.00). No infestation was recorded in the remaining genotypes.

Similar trend reaction was noticed at 56 and 63 DAE. The number of dead hearts and per cent dead hearts ranged from 0.00 to 0.05 and 0.00 to 4.92 as well as 0.00 to 0.06 and 0.00 to 5.59 respectively. Less number of dead hearts was recorded in the tested genotypes.

The present study reveals that the per cent dead hearts range is very low. These findings are in conformity with those of Hussian et al. ${ }^{15}$, who recorded lowest stem borer dead hearts in genotype CSH 23 (4.87) and Vyas et al. ${ }^{16}$ who recorded $2.39 \%$ in $\mathrm{CSV} 21 \mathrm{~F}$ and $3.58 \%$ in $\mathrm{CSH}$ $20 \mathrm{MF}$ in the kharif season. The third-instar larvae migrate to the base of the plant, bore into the shoot and damage the growing point resulting in the formation of dead heart.

The harvested stems (stalk) of sorghum were stored for fodder purpose while stubbles (base of stem) were left in the field. The carryover of $C$. partellus was accomplished through the stages like larvae or pupae embedded in the stubbles and stem (stalk). The number of larvae per stubble ranged from 0.30 to 1.80 . The highest number of larvae per stubble was recorded in genotype $\mathrm{CSH} 24 \mathrm{MF}$ (1.80) followed by N-14 (1.58), CSV 216R, NTJ-3 (C) (1.50 each) and CSV 29R (1.40), while the lowest number of larvae per stubble was recorded in the least susceptible check CSH 16 (C) (0.30). The genotypes BRJ-358 (0.40) and $\mathrm{CSH} 23$ (0.50) were on par with CSH 16 compared to the popular local check Mahalaxmi 296 (1.3).

The number of pupae per stubble ranged from 0.40 to 1.70. The highest number of pupae per stubble was recorded in genotype BRJ-358 (1.7) followed by CSV 17 (1.5), NLCW-8 (1.4) and CSH 16 (C), CSH 14, NLCW12 (1.2 each). The lowest number of pupae per stubble was recorded in genotype CSV 26 (0.4) followed by $\mathrm{CSH}$ 22SS, CSH 30 (0.60 each), popular check Mahalaxmi 296, CSH 24MF, CSV 22, NTJ-3 (0.70 each) and CSV 24SS, CSV 23, CSV 216R, CSV 15, N-14 (0.80 each) (Table 2). These results indicate that the stem borer survives in crop residues during off-season. Patel and Purohit $^{17}$ recorded $16.24 \%$ larvae in stalk and $11.25 \%$ pupae in the variety CSH 16.

The authors ${ }^{17}$ also recorded mean per cent hibernation of stem borer larva and pupa through stalk as 13.75 and
2.25 respectively, whereas in case of hibernation through stubble it was 8.96 and 4.17 respectively. Thus carryover of stem borer through larval stage was higher than that of pupal stage in the rabi season. The hibernation of stem borer through stalk was more $(16.04 \%)$ than that of stubble $(13.13 \%)$ in the rabi season. Overall, hibernation of stem borer (larva + pupa) through stubble was least in variety GJ 41 (20.0\%) and highest in GJ 38 (33.75\%). Also, hibernation of stem borer through stubble was more $(26.88 \%)$ than that of stalk $(20.21 \%)$ in kharif season.

Leaf damage caused by $C$. partellus infestation is indicated by the appearance of small, elongated windows in young whorl leaves, where the young larvae have eaten the upper surface of the leaves due to stem borer scraping. The leaf damage at 42 DAE ranged from $0.00 \%$ to $33.86 \%$. The highest per cent leaf damage was recorded in genotype CSH 22SS (33.86) followed by N-13 (29.5), CSH 25 (28.0) and NTJ-3 (C) (27.0), while the lowest was recorded in genotype followed by NTJ-1 (C) (4.0), CSV 17 (5.0) and CSH 16 (C) (5.71) compared to the popular check Mahalaxmi 296 (23.52). NLCW-12 showed no leaf damage (Table 3).

At 49 DAE leaf damage ranged from $1.75 \%$ to $18.86 \%$. The genotypes CSV 22 (18.86), SSV 84 (16.67), CSH 23 (16.10) and NTJ-4 (C) (16.00) recorded highest per cent leaf damage, whereas CSH 25 (1.75), NTJ-2 (1.80) and NLCW-12 (1.85) recorded lowest per cent leaf damage compared to the checks CSH 16 (4.50), NTJ-1 (4.50) and NTJ-3 (14.33). Popular local check Mahalaxmi 296 recorded $10.67 \%$ leaf damage.

At 56 DAE, leaf damage ranged from $4.29 \%$ to $21.19 \%$. The highest per cent leaf damage was recorded in the genotype CSV 22 (21.19), popular check Mahalaxmi 296 (20.14) and CSH 14 (17.74), while the lowest was recorded in genotypes NLCW-12 (4.29), N-14 (5.54) and NLCW-6 (7.17) compared to the least susceptible check CSH 16 (8.86).

At 63 DAE, leaf damage ranged from $4.11 \%$ to $18.87 \%$. The highest per cent leaf damage recorded in the genotypes SSV 84 (18.87), CSV 24 SS (18.21), popular check Mahalaxmi 296 (18.17) and CSV 216R (16.71), while genotypes N-14 (4.11), NLCW-12 (5.18), BRJ-358 (5.36) and NLCW-6 (6.94) recorded the lowest per cent leaf damage compared to the resistant check CSH 16 (8.04). These findings are in conformity with those of Muturi et $a l .{ }^{18}$, who reported $19.9 \%$ to $60.9 \%$ leaf damage by stem borer and Vyas et al. ${ }^{16}$ who reported $4.47 \%$ damaged leaves in the genotype $\mathrm{CSH} 20 \mathrm{MF}$ and $4.78 \%$ damaged leaves in genotype CSV $21 \mathrm{~F}$. The results of the present study reveal that leaf damage reduced with crop growth. Marulasiddesha et al. ${ }^{19}$ reported that the genotype SSV-7073 showed significantly less dead heart, leaf scraping, pinhole, peduncle or stem tunnelling damage compared to all other genotypes.

The number of damaged tillers and per cent tiller damage ranged from 1.60 to 2.30 and 30.77 to 46.10 


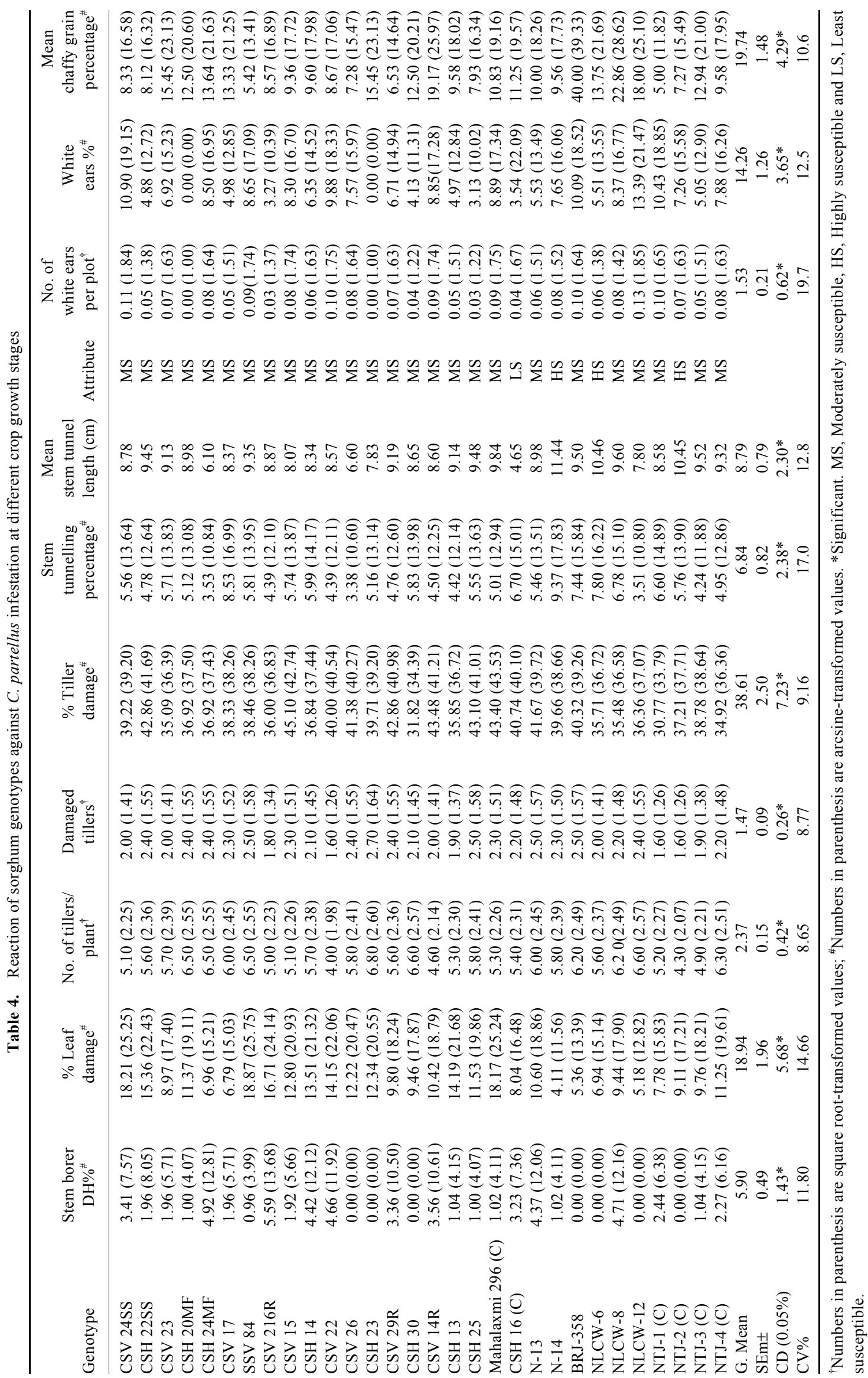


RESEARCH COMMUNICATIONS

Table 5. Correlation between stem borer infestation and larval population in sorghum

\begin{tabular}{lccccc}
\hline Parameter & \% Damaged leaves & \% Tiller damage & \% Dead hearts & \% Stem tunnelling & \% White ears \\
\hline No. of larvae per plant & 0.1316 & -0.0181 & -0.2690 & 0.2212 & 0.0745 \\
\hline
\end{tabular}

*Significant at $5 \% ; r$ table value $=0.361 ;$ Number of observations $=30$.

respectively. The highest per cent tiller damage was recorded in genotype CSV 15 (45.10) followed by CSV 14R (43.48), popular check Mahalaxmi 296 (43.40) and CSH 25 (43.10), while the lowest in the genotypes NTJ-1 (C) (30.77), CSH 30 (31.82), NTJ-4 (C) (34.92) and CSV 23 (35.09) compared to the resistant check CSH 16 (40.74) (Table 4). Mane et al. ${ }^{20}$ reported that 3.16 tillers/plant was formed, out of which 2.48 tillers $(78.5 \%)$ were damaged due to stem borer. Tiller production due to deadhearts, serves as a component of tolerance.

After causing damage to the growing point of the plant, C. partellus continues to feed inside the stem throughout the crop growth and makes tunnels inside the stem. The mean stem tunnel length ranged from 6.60 to $10.46 \mathrm{~cm}$ with 3.38-7.80\% tunnelling (Table 3). Marulasiddesha et al. ${ }^{19}$ recorded $32.57 \%$ stem tunnelling in genotype SSV 84 and $49.15 \%$ in $\mathrm{CSH} 14$. Based on mean stem tunnel length the genotypes were categorized as least susceptible $(0-5 \mathrm{~cm})$, moderately susceptible $(5-10 \mathrm{~cm})$ and highly susceptible $(>10 \mathrm{~cm})$. The genotype resistant check $\mathrm{CSH}$ 16 (C) was found least susceptible with $4.65 \mathrm{~cm}$, whereas, NTJ-2 (C), NLCW-6 and N-14 were found to be highly susceptible as they recorded mean stem tunnel length of $10.45,10.46$ and $11.44 \mathrm{~cm}$ respectively. The remaining genotypes were found to be moderately susceptible with $6.60-9.84 \mathrm{~cm}$ mean stem tunnel length.

With regard to white ears, there was significant variation among the genotypes; it ranged from $0 \%$ to $13.39 \%$ (Table 4). The genotypes NLCW-12 (13.39) followed by CSV 24SS (10.90) and NTJ-1 (C) (10.43) recorded the highest per cent white ears, whereas genotypes CSH 25 (3.13), CSV 216R (3.27) and CSH 30 (4.13) showed lesser value compared to the popular check Mahalaxmi 296 (8.89) and resistant check CSH 16 (3.54). CSH 20MF and CSH 23 did not record any white ears.

The chaffy grains recorded from the 30 genotypes ranged from $5.00 \%$ to $40.00 \%$. The genotype BRJ-358 significantly differed from the others by recording the highest chaffy grain $40.00 \%$ followed by NLCW-8 (22.86\%), CSV 14R (19.17\%) and NLCW-12 (18.00\%), whereas the lowest was in the genotype NTJ-1 (C) (5.00\%) followed by SSV 84 (5.42\%), NTJ-2 (C) (7.27\%) and CSV $26(7.28 \%)$ when compared to the popular check Mahalaxmi 296 (10.83\%) and CSH 16 (11.25\%).

There was non-significant positive correlation between the number of larvae per plant and per cent damaged leaves, stem tunnelling, white ears, chaffy grain and dead hearts respectively and negative correlation with per cent tiller damage (Table 5).
1. Agricultural Census. In Proceedings in ICAR workshop on Global Consultation on Millets Promotion for Health and Nutrition Security, Directorate of Economics and Statistics, Department of Agriculture and Cooperation, Government of India, 23 December 2013, p. 5 .

2. Agricultural Statistics at a Glance - Andhra Pradesh, 2012-2013, pp. $97-99$

3. Duale, A. H. and Nwanze, K. F., Incidence and distribution in sorghum of the spotted stem borer Chilo partellus and associated natural enemies in farmers' fields in Andhra Pradesh and Maharashtra states. Int. J. Pest Manage., 1999, 45(1), 3-7.

4. Borad, P. K. and Mittal, V. P., Assessment of losses caused by pest complex to sorghum hybrid CSH-5. Indian J. Entomol., 1983, 15, 271-78.

5. Anon., Medium-term plan. International Crops Research Institute for the Semi Arid Tropics, Patancheru, 1992, vii-viii.

6. Pawar, V. M., Jadhav, G. D. and Kadam, B. S., Compatibility of oncol $50 \mathrm{sp}$ with different fungicides on sorghum (C53541) against shoot fly (Atherigona soccata Rondani). Pesticides, 1984, 8, 9-10.

7. Sharma, H. C., Host plant resistance to insects in sorghum and its role in integrated pest management. Crop Protect., 1993, 12, 11-34.

8. Umakanth, A. V., Seetharama, N., Kumar, R. M. and Kumari, V. S. S. K., Evaluation of sorghum genotypes for their suitability in rice fallows in vertisols. In Extended Summeries, International Symposium on Rice, New Delhi 4-6 October 2004, pp. 317-318.

9. Rajasekhar, L. and Srivastav, C. P., Screening of maize genotypes against stem borer Chilo partellus in kharif season. Int. J. Appl. Biol. Pharm. Technol., 2013, 4(4), 394-403.

10. Mohan, B. R., Verma, A. N. and Singh, S. P., Population build up of Chilo partellus (Swinhoe) on forage sorghum in Haryana. $J$. Insect Sci., 1990, 3, 42-46.

11. Jotwani, M. G., Chaudhari, S. and Singh, S. P., Mechanism of resistance to Chilo partellus (Swinhoe) in sorghum. Indian J. Entomol., 1978, 40, 273-276.

12. Painter, R. H., Insect Resistance in Crop Plants, McMillan, New York, USA, 1951, p. 521.

13. Singh, B. U. and Rana, B. S., Influence of verietal resistance on oviposition and larval development of stalk-borer Chilo partellus Swinhoe and its relationship to field resistance in sorghum. Insect Sci. Appl., 1984, 5, 287-296.

14. Lal, G. and Sukhani, T. R., Antibiotic effects of sonic resistant lines of sorghum on post-larval development of Chilo partellus (Swinhoe). Indian J. Agric. Sci., 1982, 52, 127-129.

15. Hussian, T., Vyas, A. K., Sumeriya, H. K. and Ameta, O. P., Evaluation of breeder materials in advanced trails against major insect pests of sorghum. Ann. Agri-Bio Res., 2014, 19(1), 85-89.

16. Vyas, A. K., Hussian, T., Sumeriya, H. K. and Ameta, O. P., Response of various sorghum (Sorghum bicolor (L.) Moench) genotypes against major insects-pests in south Rajasthan conditions. Ann. Agri-Bio Res., 2014, 19(1), 90-92.

17. Patel, D. R. and Purohit, M. S., Seasonal abundance of parasitoids of stem borer, Chilo partellus on rabi sorghum. Insect Environ., 2012, 18(1\&2), 29-31.

18. Muturi, P. W., Rubaihayo, P., Mgonja, M., Kyamanywa, S., Kibuka, J. and Sharma, H. C., New sources of resistance to spotted stem borer, Chilo partellus in sorghum. Int. J. Agron. Agric. Res., 2012, 2(8), 18-28. 
19. Marulasiddesha, K. N., Sankar, M. and Gouda, R. G. K. R., Screening of sorghum genotypes for resistance to damage caused by the stem borer Chilo partellus (Swinhoe). Spanish J. Agric. Res., 2007, 5(1), 79-81.

20. Mane et al., 2008.

ACKNOWLEDGEMENTS. We are thankful to Directorate of Sorgum research, Rajendranagar, Hyderabad, Telangana state for providing seed material for conducting this research work and providing information on various genotypes which were used in research.

Received 5 September 2018; revised accepted 7 January 2019

doi: $10.18520 / \mathrm{cs} / \mathrm{v} 117 / \mathrm{i} 4 / 692-699$

\section{Burrow morphology of the ocypodid crab Ocypode ceratophthalma at Chandipur Coast, Eastern India and its implications}

\author{
Jyotirmoy Paul ${ }^{1, *}$, Subhronil Mondal ${ }^{2}$, \\ Rishikesh Kayal ${ }^{3}$ and Deepjay Sarkar ${ }^{4}$ \\ ${ }^{1}$ Centre for Earth Sciences, Indian Institute of Science, \\ Bengaluru 560 012, India \\ ${ }^{2}$ Department of Geology, University of Calcutta, 35, B.C. Road, \\ Kolkata 700 019, India \\ ${ }^{3} 461$, P. N. Dey Road, West Rajapur, Kolkata 700 032, India \\ ${ }^{4}$ Department of Geology and Geophysics, \\ Indian Institute of Technology, Kharagpur 721 302, India
}

Several burrow morphological features of crab $O c y$ pode ceratophthalma including burrow diameter, orientation, inclination, branching and volume were studied from Chandipur, a sedimentologically and biologically diverse beach on the eastern Indian coast. Burrow morphologies (e.g. $I, J, Y$ ) were independent of their positions with respect to the coast line. In addition, no correlation between burrow morphology and burrow diameter was observed; however, diameter of burrow appeared to be a good proxy of the total amount of sediment excavated. Burrow diameters are significantly smaller in the foreshore compared to that of the backshore, suggesting that larger individuals reside along the backshore, where they excavate deeper and large-diameter burrows to minimize chances of desiccation. Smaller burrows are more or less vertical, whereas larger burrows are inclined towards the land, probably to stabilize their domicile from tidal

*For correspondence. (e-mail: jyotirmoyp@iisc.ac.in) activities, as well as to minimize energy required to excavate sediments. All these suggest that different types of abiotic factors determine the Ocypode burrow morphology and their habitat segregation.

Keywords: Chandipur, crab burrow morphology, crab energetic, Ocypodidae.

THE semi-terrestrial, burrowing crabs of the family Ocypodidae are most common along almost all the tropical and subtropical coastlines of the world ${ }^{1,2}$. Among them, ghost crabs of the genus Ocypode ${ }^{3}$ are common members of sandy beaches all over the world. They live across a wide range of coastal zones and make characteristic burrows ${ }^{1,2,4,5}$. Burrows made by these crabs mainly act as shelters from natural environmental stress, a refuge from both aerial and terrestrial predators, as well as a place for reproduction and moulting ${ }^{6,7}$. The most characteristic feature of burrows produced by Ocypode spp. is that their burrows are morphologically diverse and vary from simply straight, unbranched, I-shaped burrows grading to more complex, gently curved and branched U, V, and Y-shaped ones to multi-branched, spiral burrows ${ }^{2,8-12}$. Moreover, burrow morphology of these ghost crabs does not vary with $\operatorname{sex}^{8,13}$. Secondly, the spatial distribution of these different types of burrows along the sandy, coastal beaches is non-random depending on burrow diameter, vertical depth, length and orientation. Their complexity increases from the foreshore to the backshore region $^{5,8,9,12,13}$.

These large arrays of burrow morphologies produced by members of the family Ocypodidae are speciesspecific $^{2,7,8,11}$, although they may also depend upon several abiotic/environmental factors, such as geography and geomorphology (slope, vegetation cover, salinity, groundwater table and tidal cycle) and substrate properties (compactness and composition) ${ }^{5,13-17}$. Other biological factors, like size and ontogeny, can also affect the overall morphology of these burrows ${ }^{5,8,14,15}$. Unfortunately, to-date, there is no consensus regarding the major causes influencing the three-dimensional morphology of Ocypode crab burrows. Although there are plenty of studies on burrow morphologies, no studies have yet studied the energetics of the burrow excavation as a potential factor influencing the burrow morphology, at least for the ghost crabs. In the present study, we collected data of Ocypode crab burrow morphologies from Chandipur, the eastern part of India to identify the nature of morphological complexity (diameters, inclinations, orientation, length and depth, and three-dimensional morphology) and interpret how the burrow morphology is affected by several abiotic factors at Chandipur coast.

The present study was conducted at Chandipur $\left(21^{\circ} 27^{\prime} 45.17^{\prime \prime} \mathrm{N}, 87^{\circ} 3^{\prime} 21.57^{\prime \prime} \mathrm{E}\right)$ near the confluence of the river Burahbalang with the Bay of Bengal (Figure 1). The coastal area of Chandipur is characterized by a wide 